\title{
Structure and Propagation of a Large Cyclonic Eddy in the Western North Pacific from Analysis of XBT and Altimetry Data and Numeri- cal Simulation
}

\author{
I-Huan Lee ${ }^{1, *}$, Wen-Ssn Chuang ${ }^{1}$, and Dong-Ping Wang ${ }^{2}$ \\ (Manuscript received 26 December 2002, in final form 22 April 2003)
}

\begin{abstract}
The Kuroshio transport east of Taiwan dropped precipitously at the beginning of 1995. At the same time a large cyclonic eddy was spotted in the general vicinity. The time history and vertical structure of this eddy, which originated from the subtropical North Pacific, are reconstructed using XBT and T/P altimetry data. Our results show that dynamic heights calculated from the XBT with reference level to $500 \mathrm{~m}$ agree well with satellite-derived sea surface height anomalies (SSHA). Application of the Empirical Orthogonal Function (EOF) analysis to XBT data shows that the first mode alone, which explains $75 \%$ of the total temperature variance, captures most of the eddy structure. The second mode, which explains most of the remaining variance, reflects the redistribution of vertical temperature structure at the trail of the eddy. The cyclonic eddy propagated in the northwest direction with an averaged speed of about $10 \mathrm{~km} /$ day. A quasi-geostrophic model is applied to examine the eddy propagation. The model result suggests that a northward background baroclinic flow of $6 \mathrm{~km} / \mathrm{day}$ can account for the observed northward propagation. The model also predicts the formation of a strong anticyclonic eddy at the wake of the cyclonic eddy.
\end{abstract}

\section{INTRODUCTION}

The Kuroshio enters the East China Sea through the East Taiwan Channel (ETC), a shallow $(<1000 \mathrm{~m})$ ridge between the coast of Taiwan and the southernmost Ryukyu Island of Iriomote (Fig.1). During the World Ocean Circulation Experiment (WOCE), the Kuroshio transport through ETC was measured using dense network of moored current meters, PCM-1, for about eighteen months between September 1994 to May 1996 (Johns et al. 2001). The mean transport during this period was $21.5 \mathrm{~Sv}$. For comparison, the mean transport through Florida Strait is about 31.7 Sv (Leaman et al. 1987). On the other hand, the Kuroshio wansport

\footnotetext{
${ }^{1}$ Institute of Oceanography, National Taiwan University, Taipie, Taiwan

${ }^{2}$ Marine Science Research Center, Stony Brook University, Long Island, New York

* Corresponding author address: Dr. I-Huan Lee, Institute of Oceanography, National Taiwan University. \#1, section 4, Roosevelt Road, Taipie, 106, Taiwan; E-mail: d85241001@ntu.edu.tw
} 


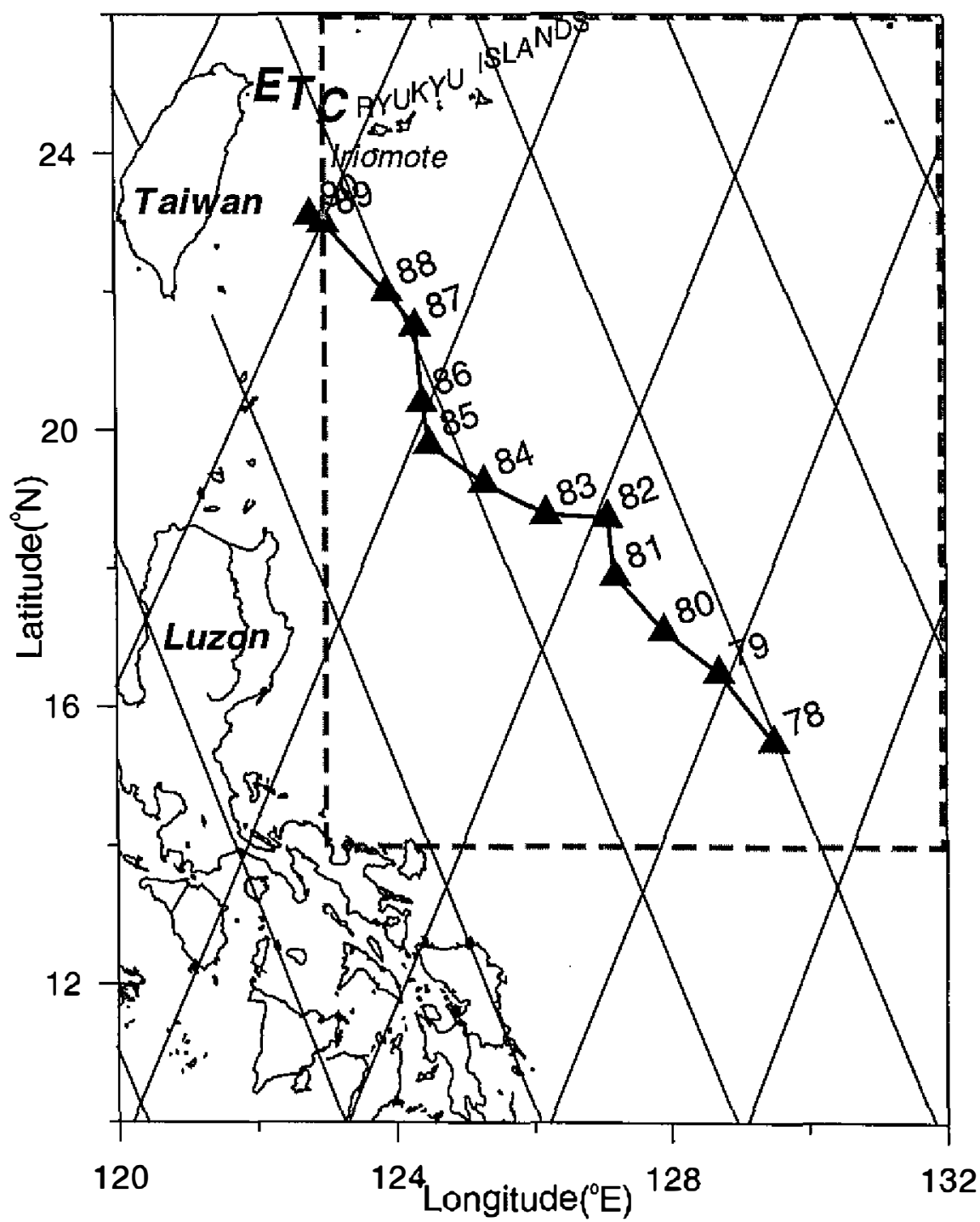

Fig. 1. TOPEX/POSEIDON (T/P) ground tracks (solid lines) and the trajectory of eddy $9410 \mathrm{~L}$ from cycle 78 to cycle 90 . The study area is enclosed in the dashed line.

had large fluctuations with amplitudes of about $10 \mathrm{~Sv}$, whereas such signals are much weaker in the Florida Current (Niier and Richardson 1973); presumably in the latter case, interior mesoscale eddies are blocked by the Bahamas. The potential link between the Kuroshio fluctuations and the interior eddies has attracted considerable interests. Yang et al. (1999) found that low Kuroshio transports were associated with negative area-averaged (between $22^{\circ} \mathrm{N}$ and $25^{\circ} \mathrm{N}$ and $122^{\circ} \mathrm{E}$ and $125^{\circ} \mathrm{E}$ ) sea surface height anomalies (SSHA). They suggested that the transport decrease could be caused by the impinging cyclonic eddies. Zhang et al. (2001), 
furthermore, suggested that the transport decrease through ETC could result from the offshore deflection of the Kuroshio path. They, however, associated the anomalous Kuroshio path with the impinging anticyclonic eddies. In both studies, the interior eddies are inferred from SSHA, and the ambiguity is due partly to difficulties in separating the Kuroshio meanders from isolated eddies.

In the western North Pacific the mesoscale eddy activities are greatly enriched in a zonal band centered at $22^{\circ} \mathrm{N}$ of the tropical/subtropical front boundary (Qiu 1999). Based on 30 XBT/XCTD transects between San Francisco and Taiwan from 1991 to 1999, Roemmich and Gilson (2001) identified over 400 such eddies. A typical ('composite') eddy had wavelength of $500 \mathrm{~km}$, dynamic height amplitude of $15 \mathrm{dyn} \mathrm{cm}$, and maximum temperature anomaly of 2 . $2^{\circ} \mathrm{C}$ located at $160 \mathrm{~m}$. Most of the observed eddies propagated westward at about $10 \mathrm{~cm} \mathrm{~s}^{-1}$; however, since their data were taken along an east-west transact, it was not possible to tell if some eddies might also have significant north-south propagation.

During PCM1, the lowest measured transport through ETC occurred in early March 1995 (Zhang et al. 2001), which was a major event throughout the entire observation. The Kuroshio transport started to decrease in January, and after a brief recovery in February, dropped sharply again in March. During this period, a large cyclonic eddy ("9410L") was spotted (based on SSHA) in the general vicinity (Yang et al. 1999). In this study, we track the evolution of eddy $9410 \mathrm{~L}$ by adding XBT observations. We show that the observed SSHA feature is supported by the XBT observations. Also, eddy $9410 \mathrm{~L}$ is much stronger (dynamic height $>60$ dyn $\mathrm{cm}$ ) than the typical eddy of Roemmich and Gilson (2001). It is useful to find out if eddy 9410L's internal temperature structure is similar to that of their composite eddy. Finally, eddy $9410 \mathrm{~L}$ has a large northward propagation speed. We use a simple model to explain this anomalous behavior.

\section{DATA}

\subsection{TOPEX/POSEIDON Altimetry}

The altimetry data are obtained from Center for Archiving, Validation, and Interpretation of Satellite Data in Oceanography, France (AVISO 1992). The satellite orbit has a repeat cycle period of about 10 days. The along-track resolution is $5.8 \mathrm{~km}$ between points. At the equator the ground track separation is $315 \mathrm{~km}$ and the inclination is $66^{\circ}$. Corrections of instrumental errors and atmospheric effects are described in Hwang (1996). The Cartwright and Ray (1991) model tidal data (CSR3.0) are applied to the tidal correction. Five-year averaged sea surface heights from 1993 to 1998 are removed and ocean waves also are filtered. The SSHA data from cycle 78 (26 October 1994) to cycle 90 (22 February 1995) are used in this study.

Figure 1 displays the T/P ground tracks in $10^{\circ}-25^{\circ} \mathrm{N}$ and $120^{\circ}-132^{\circ} \mathrm{E}$. In order to compare SSHA with dynamic heights, along track SSHA data are interpolated to create two-dimensional gridded data. The altimetry data are sub-sampled every five points, low passed with 40 $\mathrm{km}$ along track, and objectively mapped using optimum interpolation (OI) (Rutherford 1972) with resolution of $0.25 \times 0.25$ degree and a search radius of $150 \mathrm{~km}$. The maximum interpolation error, based on OI error estimation, is about $6 \mathrm{~cm}$. The trajectory of eddy $9410 \mathrm{~L}$ can be 
charted by the position of the SSHA minimum at each T/P cycle (Fig.1). The cyclonic eddy 9410L first appeared on cycle 78. It propagated northwestward with a speed of $6.5 \mathrm{~km} / \mathrm{day}$ westward and $7.5 \mathrm{~km} /$ day northward. The cyclonic eddy merged with the Kuroshio on cycle 90 .

\subsection{CTD and XBT Profiles}

CTD and XBT data are obtained from National Ocean Data Center (NODC). During the study period very few CTD stations were available. To examine the relationship between dynamic height and internal density structure, we use data from WOCE repeat transect PR20, which spans from the southern tip of Taiwan to about $950 \mathrm{~km}$ eastward. The distance between two CTD stations is $0.16^{\circ}$ west of $123^{\circ} \mathrm{E}$ and increases to $0.5^{\circ}$ further east. There were two PR20 surveys, one at 11-15 October 1990, and the other at 26-29 June 1991. All CTD profile depths are $>1000 \mathrm{~m}$, except for the two shallow stations near Taiwan.

Over 150 XBT profiles are available from October 1994 to February 1995 in the study area $\left(122^{\circ} \mathrm{E}\right.$ to $132^{\circ} \mathrm{E}, 12^{\circ} \mathrm{N}$ to $\left.24^{\circ} \mathrm{N}\right)$. The typical XBT profile depth is $500 \mathrm{~m}$, which is used as the reference level. For stations whose maximum depth is $<500 \mathrm{~m}$ (but $>300 \mathrm{~m}$ ), the missing data are filled with the "climatology", the averaged temperature profile is thus calculated from all available data during this period. Of the resulting profiles, $41 \%$ have the complete depth range, $57 \%$ are filled with one level $(500 \mathrm{~m})$ and $2 \%$ are filled with two levels $(400 \mathrm{~m}$ and 500 $\mathrm{m})$. The standard deviation of the temperature for $500 \mathrm{~m}$ depth among these available data is 0 . $96^{\circ} \mathrm{C}$, so the filled-in temperature would not cause a significant variation on the dynamic height.

Because the absolute sea surface height (SSH) is not known, SSHA can be compared with dynamic heights only in regions of small mean SSH gradient. In the western North Pacific, the mean dynamic topography is dominated by the Kuroshio and the Subtropical Front (Qu et al. 1999 ). We therefore limit XBT profiles to a rectangular area east of the Kuroshio and north of the Subtropical Front (Fig.1). Figure 2 shows XBT stations superposed on SSHA for cycles 80-85 (15 November 1994 to 4 January 1995) and 89-90 (12 to 22 February 1995). (There were no XBT data in cycles 86-88.) There were 24 profiles during C80 to C85 when the cyclonic eddy was in the study area, and 53 profiles during C 89 to C90 when the cyclonic eddy had already left the region.

\section{RESULTS}

\subsection{Dynamic Height Calculation}

Dynamic heights preferably should be calculated from the CTD profiles using a reference level as deep as practicable. However, since only XBT profiles of $500 \mathrm{~m}$ deep are available, it is necessary to demonstrate that the baroclinic field is confined mainly to the upper $500 \mathrm{~m}$ and the density variation is determined mainly by the temperature field. We use the two PR20 surveys to test the sensitivity of dynamicheight calculation. Figure 3 compares dynamic heights calculated using reference levels of $500 \mathrm{~m}$ (DH_500) and $1000 \mathrm{~m}$ (DH_1000). The dynamic height generally increases towards the east with a steep rise across the Kuroshio. The variation 

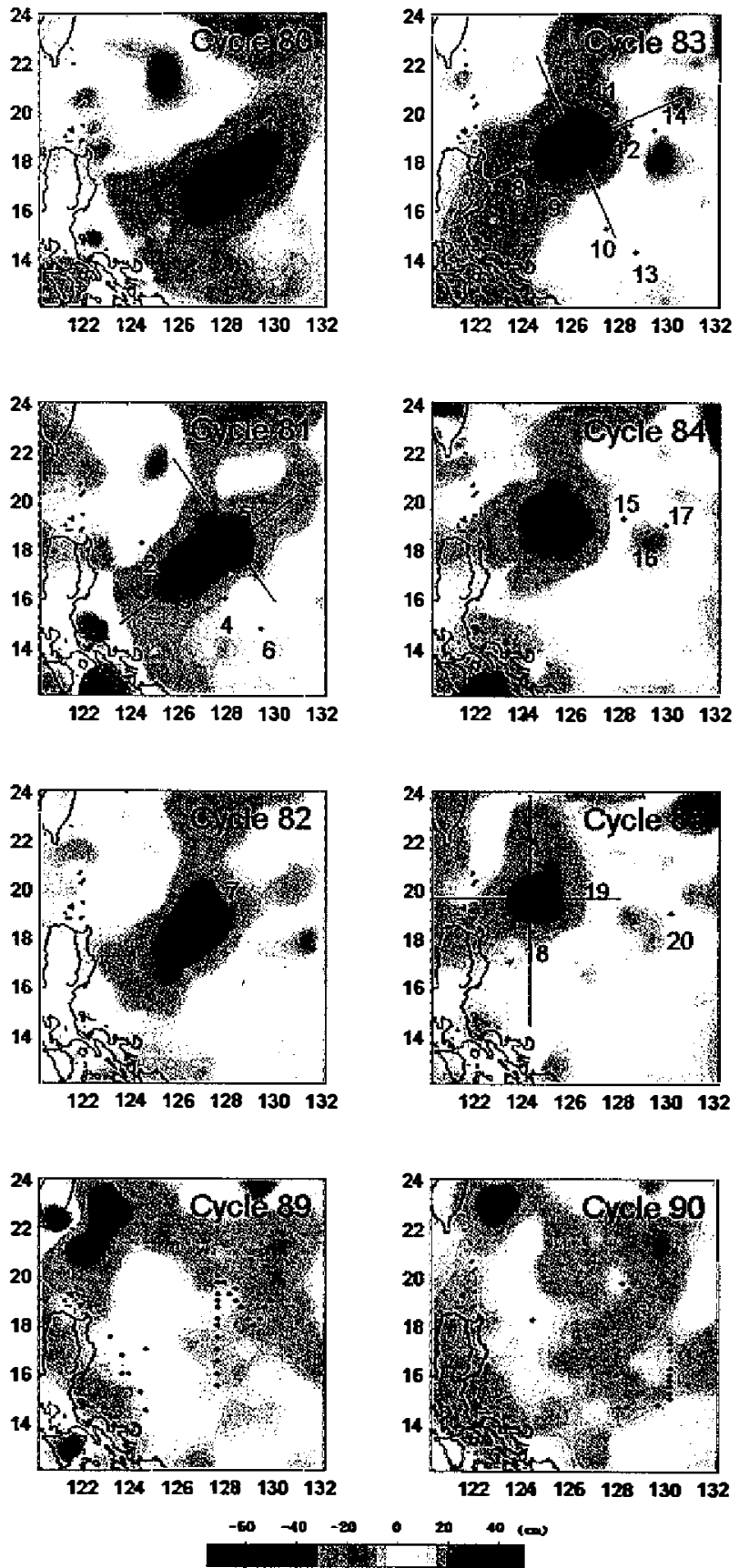

Fig. 2. The sea surface height anomaly (SSHA) maps with the XBT stations $(\bullet)$ during cycle 80 to cycle 85 (top six), and cycles 89 and 90 . Solid lines marked in cycles 81,83 and 85 denote the major and minor axes of eddy 9410L. 
of difference between DH_1000 and DH_500 with mean of the difference removed typically is $<5$ dyn cm, except in the Kuroshio (west of $123^{\circ} \mathrm{E}$ ) where the difference can be as large as 15 dyn $\mathrm{cm}$. Figure 4(a) compares the regression of DH_500 with DH_1000 east of $123^{\circ} \mathrm{E}$. The correlation coefficient is 0.97 and the standard error is $2.2 \mathrm{dyn} \mathrm{cm}$. This indicates that east of the Kuroshio the baroclinic contribution is small below $500 \mathrm{~m}$. To estimate the salinity effect, dynamic heights calculated from the temperature profiles using a standard salinity profile are compared with those calculated from the CTD profiles (Figs. 4b, c, d); the standard salinity profile is obtained by averaging of all PR20 salinity profiles. The correlation coefficient is 0 . 99 and the standard error is about 2 dyn $\mathrm{cm}$. Obviously, the horizontal salinity variation is not important.

\subsection{Comparison of SSHA with Dynamic Height}

The XBT data can be arranged into two groups, one associated with the eddy (C80 to $\mathrm{C} 85$ ) and the other with the background (C89 and C90). Figure 5 compares dynamic heights (reference level $=500 \mathrm{~m}$ ) with SSHA for these two groups. In the first group where the SSHA range is large, from about $-60 \mathrm{~cm}$ to $20 \mathrm{~cm}$, the correlation coefficient is 0.89 and the error is $8.2 \mathrm{~cm}$. In the second group, the data range is small, the correlation is poor, and the standard error of $2.6 \mathrm{~cm}$ is in essence a measure of background noise. Both groups, however, have identical mean value of about 160 dyn $\mathrm{cm}$, indicating a consistent mean background. Based on the regression fit from the first group, SSHA and dynamic height (DH) can be related,

$$
\mathrm{DH}=\mathrm{SSHA}+160+\mathrm{O}(8) \text { dyn } \mathrm{cm} \text {. }
$$

\subsection{Reconstruction of Eddy $9410 \mathrm{~L}$}

The 20 XBT profiles of C80 to C85 are decomposed using the method of Empirical Orthogonal Function (EOF). Figures 6a and $b$ show the EOF and Principal Component (PC) of the first two leading modes. The first mode accounts for $75 \%$ of the total variance, and the second mode $18 \%$. The first EOF has a single maximum at $150 \mathrm{~m}$, the depth of the thermocline, and the second EOF has two maxima with zero crossing at the thermocline. The first PC shows clear separation of the cold cyclonic eddy (stations with large negative indices) from the warm anticyclonic eddy (stations with large positive indices). Station 5 has the largest cold anomaly and station 17 the largest warm anomaly. (Station locations are marked in Fig. 2.) The second PC, on the other hand, is dominated by few stations (\# 4,6, 10 and 13) of large negative indices. Its significance will be addressed in the Discussion.

The original vertical temperature profiles can be completely reconstructed from the first two EOF modes; indeed, for most of the stations the first mode alone is sufficient. This suggests that the vertical temperature profiles can be mapped from dynamic heights. Figure 7 compares dynamic heights calculated from the original and reconstructed temperature profiles. The correlation coefficient is 0.98 and the error is $3.1 \mathrm{dyn} \mathrm{cm}$. The amplitude of the first PC $(\mathrm{PCl})$ can be written as 

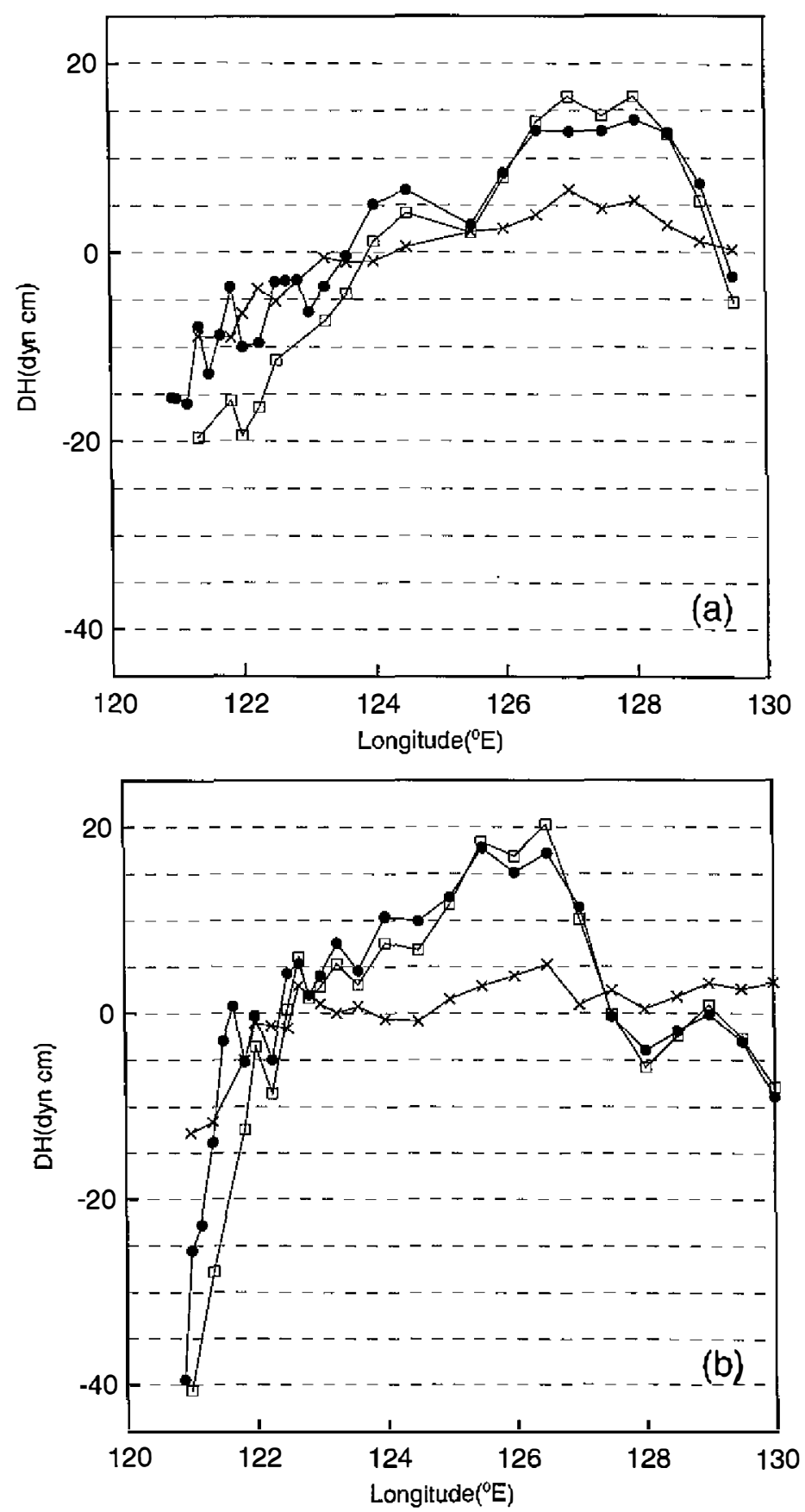

Fig. 3. The dynamic height profiles along PR20 during: (a) 11 15 October 1990 and (b) 26 29 June 1991. The symbols ' $\bullet$ ' and ' $\square$ ' denote the reference level at $500 \mathrm{~m}$ (DH_500) and $1000 \mathrm{~m}$ (DH_1000) respectively, and ' $x$ " denotes the difference of DH_1000 and $\mathrm{DH}_{\ldots} 500$. 

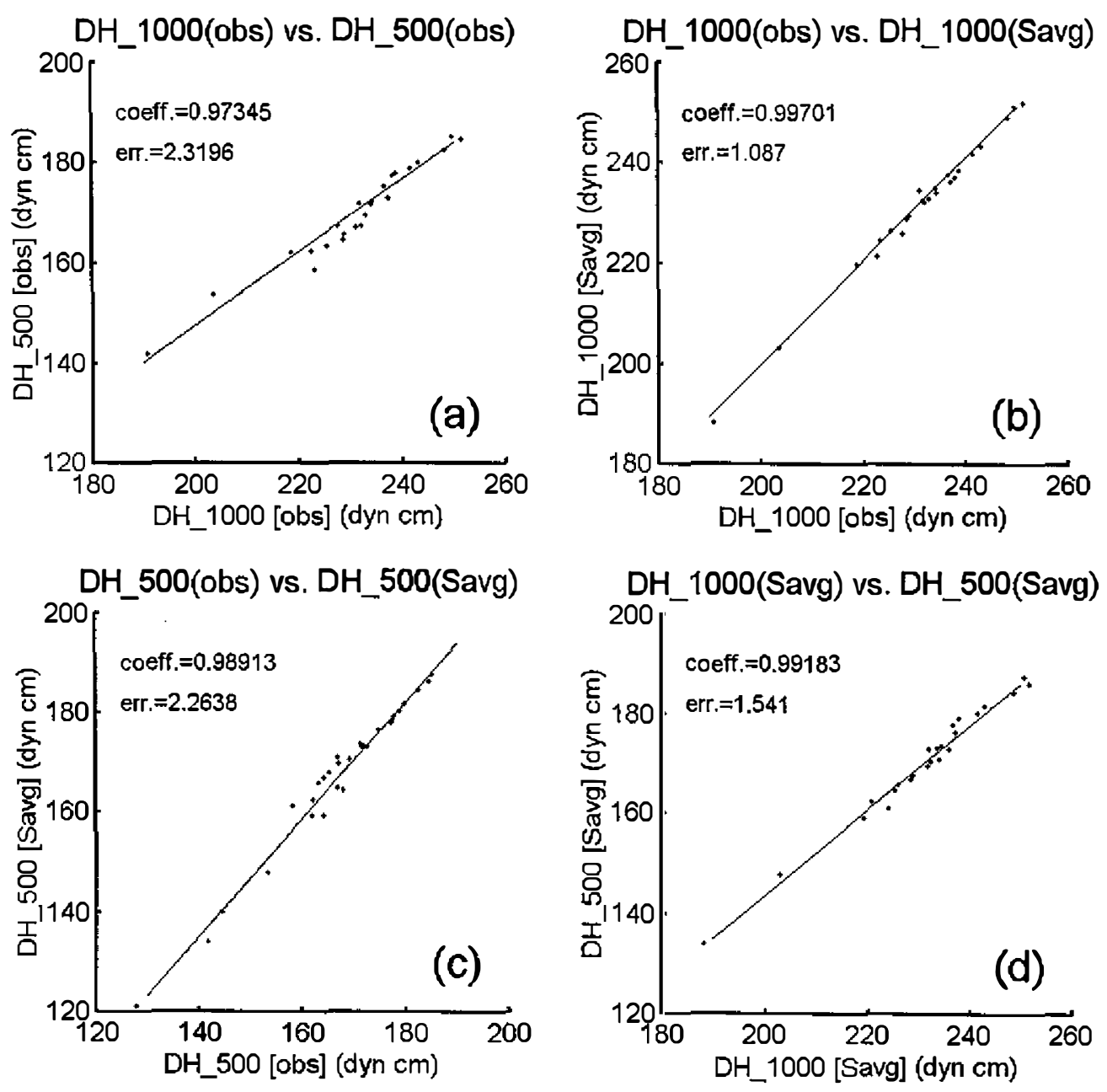

Fig. 4. Scatter diagrams of the dynamic heights (DH). DH_1000 and DH_500 denote reference levels of $1000 \mathrm{~m}$ and $500 \mathrm{~m}$ respectively, "obs" represents DH calculated from observed temperature and salinity profiles, "Savg" represents DH calculated from observed temperature profiles and salinity climatology. Correlation coefficients (coeff.) and errors (err.) are written on the upper left corner of each subplot.

or, from (1),

$$
\mathrm{PC} 1=0.3182 * \mathrm{DH}-47.6
$$

$$
\mathrm{PC} 1=0.3182 *(\text { SSHA }+160)-47.6 \text {. }
$$

Using (3) and the first EOF, SSHA can be mapped into the internal temperature structure. Figure 8 shows reconstructed cross-sectional temperature structures of $9410 \mathrm{~L}$ using first mode EOF and $\mathrm{PC} 1$ along the major and minor axes for cycles 81,83 and 85 . The major and minor axes are basically defined according the longest and shortest axes across the center (minimum 

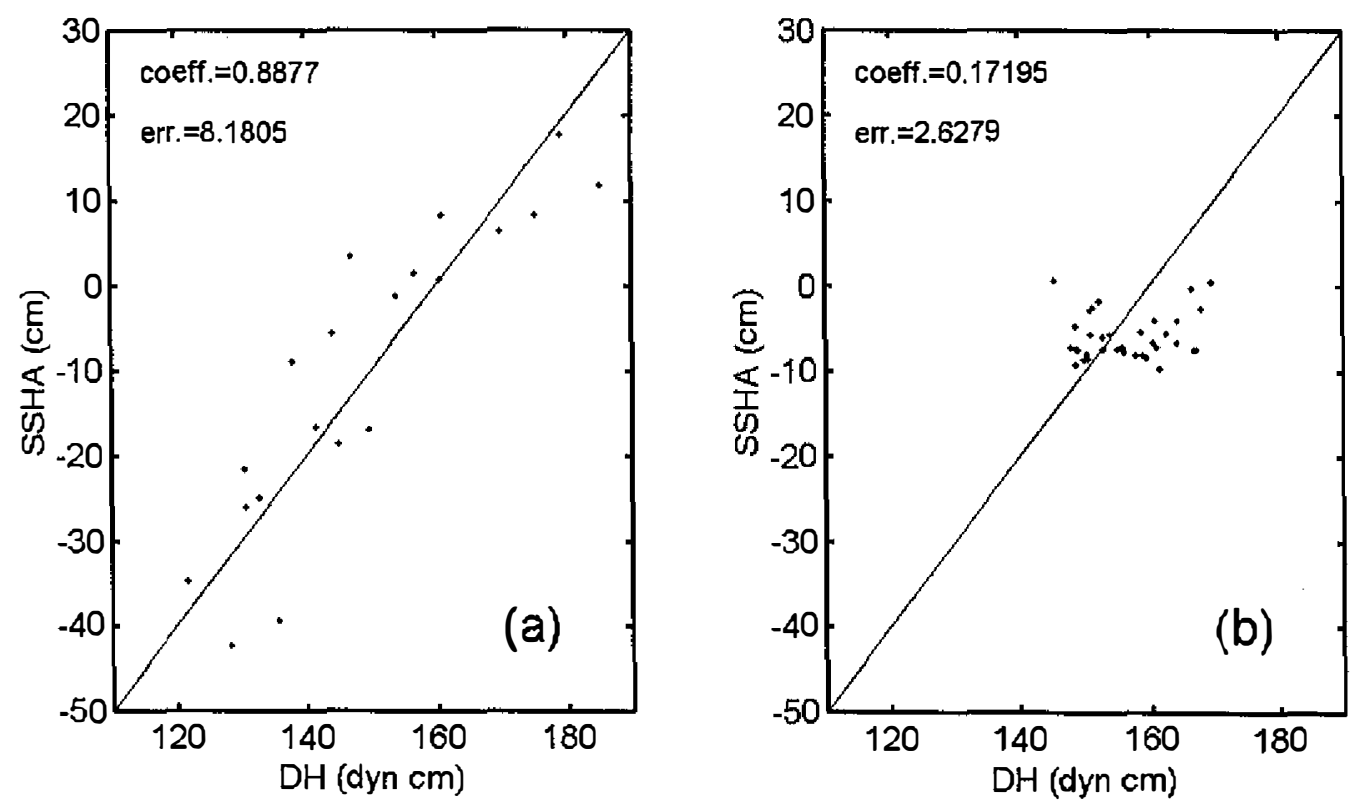

Fig. 5. Scatter diagrams between dynamic heights (DH) and sea surface height anomalies (SSHA) during (a) cycle 80 to cycle 85 and (b) cycle 89 and cycle 90. Correlation coefficients and errors are written on the upper-left corner of each subplot.

value of SSHA) of the eddy.

\subsection{Model Simulation}

Mesoscale eddies typically propagate in a predominantly westward direction. Eddy $9410 \mathrm{~L}$, however, has large northward speed (Fig.1). We use a quasi-geostrophic model to examine the eddy propagation. From the EOF analysis, most of the temperature variations can be described by the first baroclinic mode; and hence, for simplicity, a reduced gravity model is used. The governing vorticity equation on the beta plane, in terms of the stream function, is (e.g., CushmanRoisin 1994)

$$
\frac{\partial}{\partial t}\left(\zeta-\frac{1}{R d^{2}} \psi\right)+J(\psi, \zeta)+\beta_{0} \frac{\partial \psi}{\partial x}=-B_{M} \nabla^{4} \zeta-r \zeta,
$$

where $\zeta$ is the vertical component of the relative vorticity and $\psi$ is the stream function,

and

$$
\zeta=\nabla^{2} \psi
$$

$$
u=-\frac{\partial \psi}{\partial y}, \quad v=\frac{\partial \psi}{\partial x}
$$



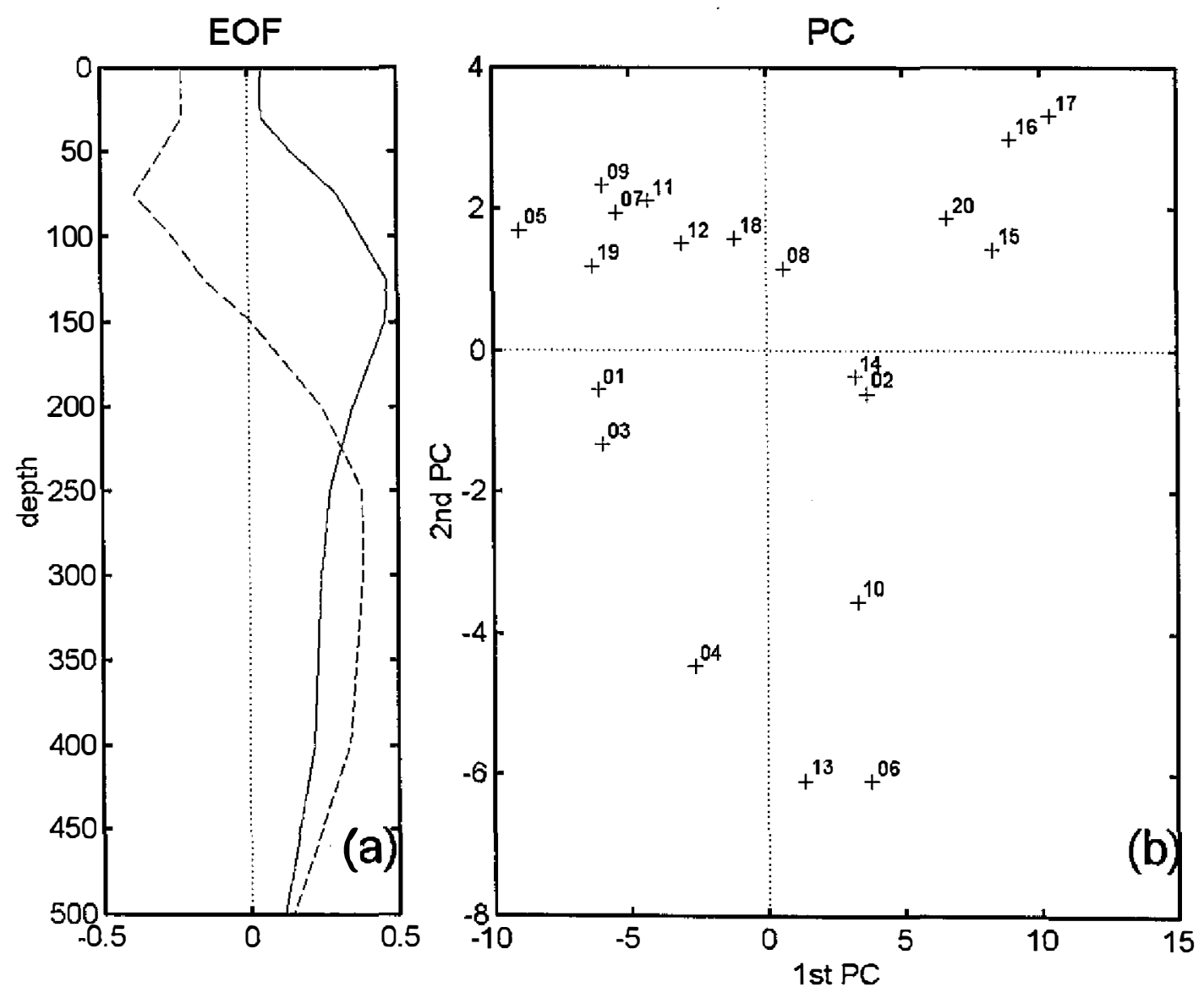

Fig. 6. Empirical Orthogonal Function (EOF) analysis. (a) The first (solid line) and second (dashed line) EOF modes. (b) Scatter diagram of the first principal component (PC) vs. the second PC. The station number is marked.

The model parameters are $B_{M}=7 \times 10^{10} \mathrm{~m}^{4} \mathrm{~s}^{-1}, r=2 \times 10^{-9} \mathrm{~s}^{-1}, \beta_{0}=2 \times 10^{-11} \mathrm{~m}^{-1} \mathrm{~s}^{-1}$, and $R d=60$ $\mathrm{km}$. The nonlinear effect, $J(\psi, \zeta)$, is essential in keeping the eddy from beta dispersion (e.g., McWilliams and Flierl 1979). The model's horizontal resolution is $20 \mathrm{~km}$, the time step is 2.4 hours, and the model is integrated for 150 days in each run.

We assume an initial field of Gaussian shape (McWilliams and Flierl 1979),

$$
\psi(x, y)=-A \cdot \exp \left[-(r / r c)^{2}\right]
$$

where $\mathrm{A}=4000 \mathrm{~m}^{2} \mathrm{~s}^{-1}, r=\sqrt{\left(x-x_{0}\right)^{2}+\left(y-y_{0}\right)^{2}}$, where $\left(\mathrm{x}_{0}, \mathrm{y}_{0}\right)$ is the initial eddy location, and $r c$ is a length scale parameter. With $r c=85 \mathrm{~km}$, the initial eddy is about $450 \mathrm{~km}$ in diameter and has maximum velocity of $39 \mathrm{~cm} \mathrm{~s}^{-1}$. The model domain is $2000 \mathrm{~km} \times 1500 \mathrm{~km}$. Double periodic boundary condition is applied. Figure 9 shows evolution of the stream function and potential vorticity (PV). The cyclonic eddy propagates westward at about $4 \mathrm{~km} /$ day, 


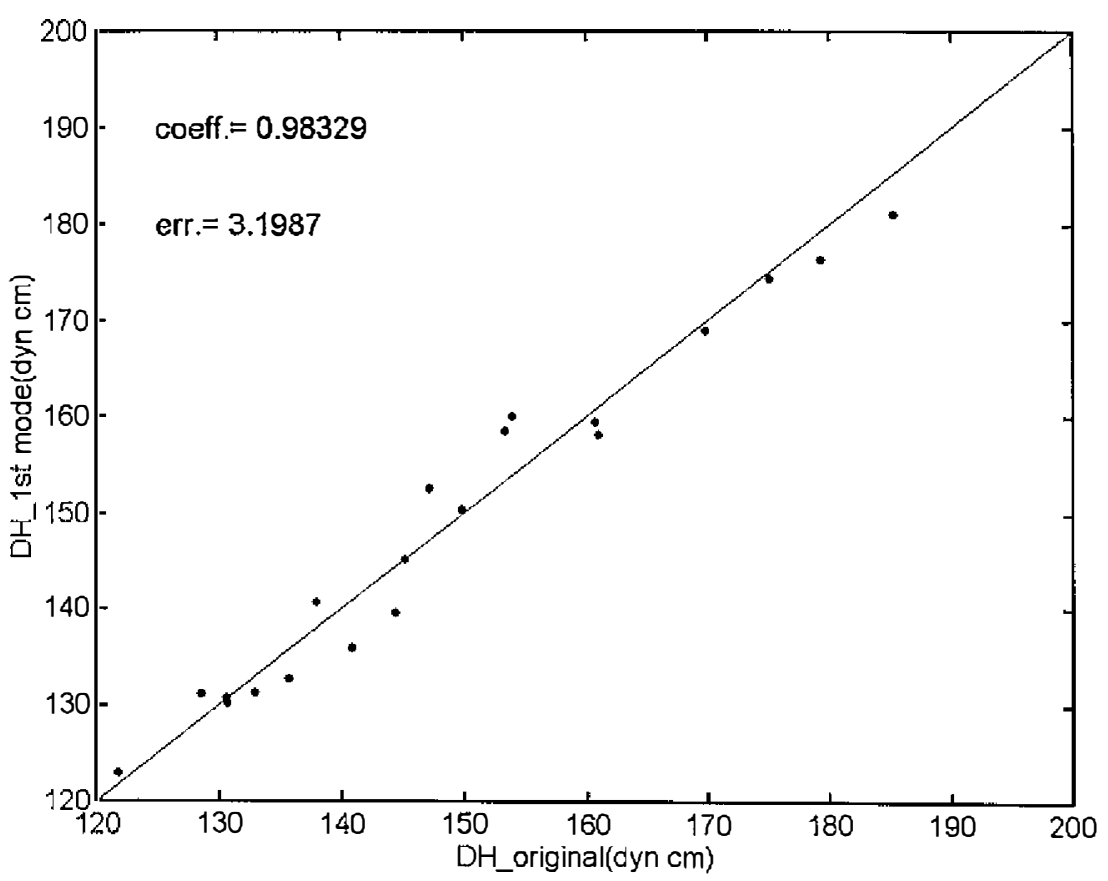

Fig. 7. Scatter diagram of the dynamic height (DH) calculated from the original $(x$-axis) and the first EOF mode reconstructed (y-axis) temperature profiles. Correlation coefficient and error are written in the upper left corner.

and has a slight northward speed of $1.5 \mathrm{~km} / \mathrm{day}$, and is trailed behind by beta dispersion waves which gradually evolve into a weak anticyclonic eddy.

The simple theory does not explain the observed northward propagation. Change of initial eddy diameter or $R d$ does not have significant effect on the phase speed. Alternatively, the northward propagation may be caused by a weak mean northward flow. The eddy path is in the subtropical gyre, and a northwestward background flow can be expected (Qu et al. 1999). Unfortunately, background dynamic height noise is too large to identify any large-scale gradient. The only evidence for a northward flow is from PR20, which shows a general rise of dynamic heights towards the east with a corresponding velocity of about $6 \mathrm{~km} /$ day (Fig. 3). We include a weak mean northward flow in the initial field,

$$
\psi(x, y)=B \cdot \sin [2 \pi \cdot(x-W / 4) / W]-A \cdot \exp \left[-(r / r c)^{2}\right]
$$

Where $\mathrm{B}=222000 \mathrm{~m}^{2} \mathrm{~s}^{-1}$, and $W$ is the width of the model. The model domain is $20000 \mathrm{~km}$ $\times 4000 \mathrm{~km}$, and the cyclonic eddy is placed in a region of nearly uniform northward flow of 6 $\mathrm{km} /$ day. One of the reasons for choosing a large model is to avoid the unnecessary nonlinear effect generated by the background flow. The other is that the cyclonic eddy would still propagate under the nearly uniform backflow. Figure 10 shows evolution of the stream function and 

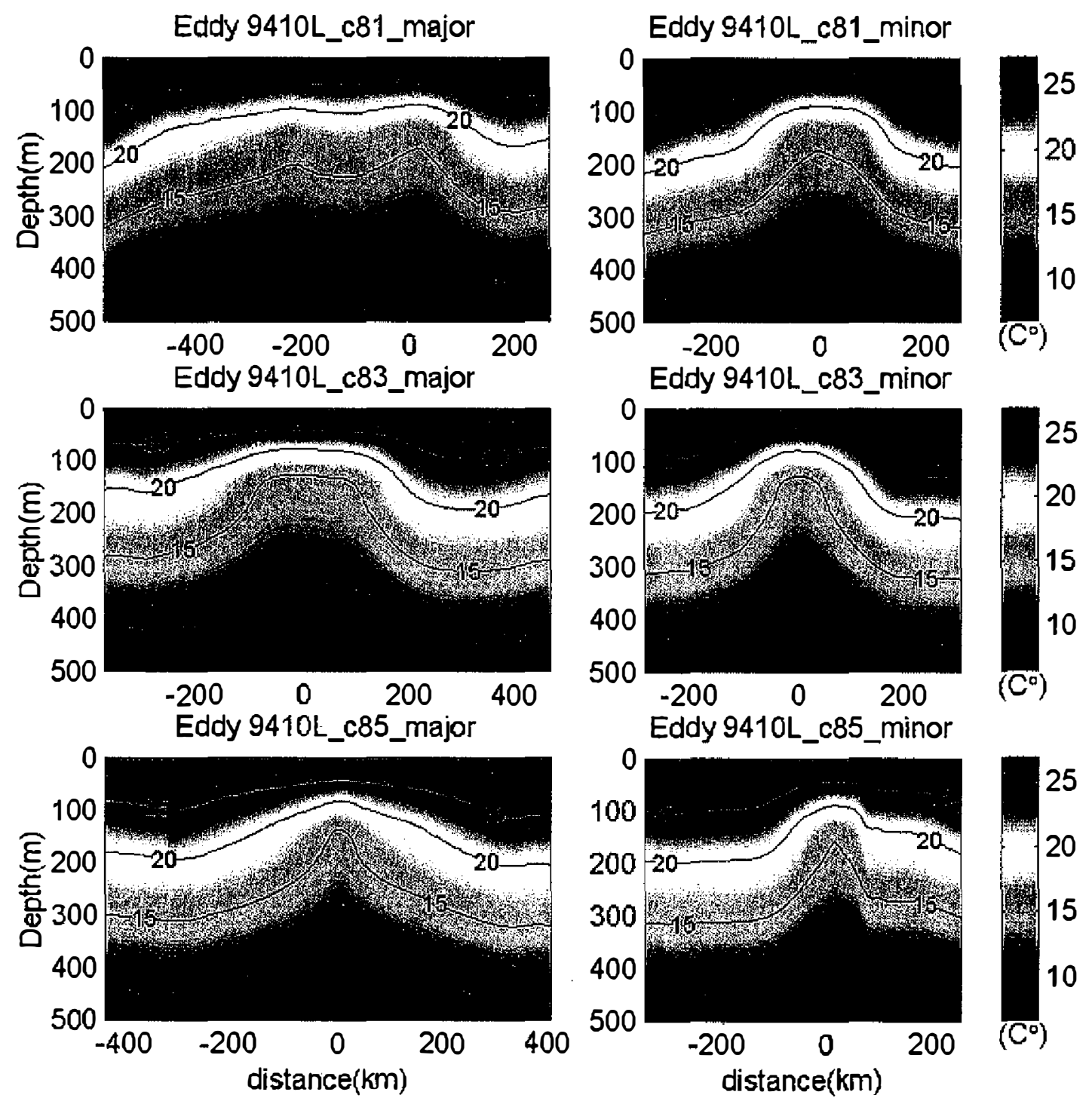

Fig. 8. The reconstructed cross--sectional temperature structures of eddy 9410L along the major (left column) and minor (right column) axes for cycles 81,83 and 85 .

potential vorticity. With a northward mean flow, PV is tilted in a northeast to southwest direction and the spatial gradient of PV is increased. The northwestward propagating eddy pulls large low PV water from behind, inducing a strong anticyclonic eddy in the trail. The westward phase speed is $5 \mathrm{~km} /$ day and the northward speed is $4 \mathrm{~km} / \mathrm{day}$. With larger $R \boldsymbol{d}(=80 \mathrm{~km})$, the northward phase speed increases to $7 \mathrm{~km} /$ day. 


\section{DISCUSSION}

We have reconstructed the temperature structure of eddy 9410L using XBT and SSHA. In regions outside of the Kuroshio (east of $123^{\circ} \mathrm{E}$ ), dynamic heights estimated from the reconstructed vertical temperature profile (in the upper $500 \mathrm{~m}$ ) are highly coherent with sea surface height anomalies. This result is very encouraging. Firstly, our results have confirmed the very presence of the large cyclonic eddy. Secondly, in ocean models it is often necessary to project (assimilate) SSHA into internal temperature structure (e.g., Mellor and Ezer 1991). Our empirical formula can be used in model applications in this eddy-rich but relatively little studied area.

Roemmich and Gilson (2001) have constructed a composite warm/cold eddy based on the repeat XBT transects in the subtropical North Pacific. In their study the maximum temperature anomaly is located at about $160 \mathrm{~m}$. Our first EOF mode has the corresponding maximum amplitude at $150 \mathrm{~m}$. They noted that the center of the temperature anomaly tilts up-and westward. In our EOF analysis, to introduce a tilt requires consideration of the second mode. The stations with large (and negative) second PC (stations 4, 6, 10 and 13; cf. Fig. 6) all are located behind the cyclonic eddy (Fig. 2). A negative index corresponds to positive temperature anomaly above the thermocline and negative temperature anomaly below the thermocline. Superposition of the two EOF modes causes the center of the temperature anomaly to slant down- and eastward (behind the eddy), in the same sense as Roemmich and Gilson (2001). Our result, although, seems to suggest that the phase tilt is a feature of the trailing edge of an isolated eddy.

The statistical results of Roemmich and Gilson (2001) show that the zone centered at $22^{\circ} \mathrm{N}$ is enriched with westward propagating eddies. The study of Qiu (1999) suggests that eddies in this zone might be generated by the baroclinic instability of subtropical fronts. Eddy $9410 \mathrm{~L}$, however, first appeared at much more lower latitude of $15^{\circ} \mathrm{N}$ then propagating northeastward. Its amplitude of sea surface height is much larger than that of the typical westward propagating eddy compiled by Roemmich and Gilson (2001). It seems to indicate that 9410L might form in different process other then those appear in the higher eddy enriched zone. A closer look at the atmospheric conditions during the formation of $9410 \mathrm{~L}$, we find two typhoons (Verne and Teresa) passed the initial position of 9410L at around the same time (Fig. 11). One of them (Typhoon Verne) even circled around the site for several days. The initial phase of 9410L, a northeast to southwest elongated shape with two minima of the 9410L (ref. C80 81 in Fig.2), is found to be distributed along the circling area of Typhoon Verne. We therefore conclude that the typhoons should be the primary mechanism for the formation of 9410L.

From the observation of T/P since 1992, we also identify several other cyclonic eddy events (e.g., 21 November $1992 \sim 31$ December 1992, figure not shown) whose track and characteristics are similar to those of $9410 \mathrm{~L}$, and not by coincidence, their initial occurrence paired with typhoon passages. However, none of them was as intense and long-lived as 9410L. In fact, a close examination of the satellite derived wind field from 1990 to 1996 (WOCE/PODAAC 1998) indicates that when typhoons Verne and Teresa intersect, they produce the strongest cyclonic wind in the low latitude of northwest Pacific during the seven-year period of 

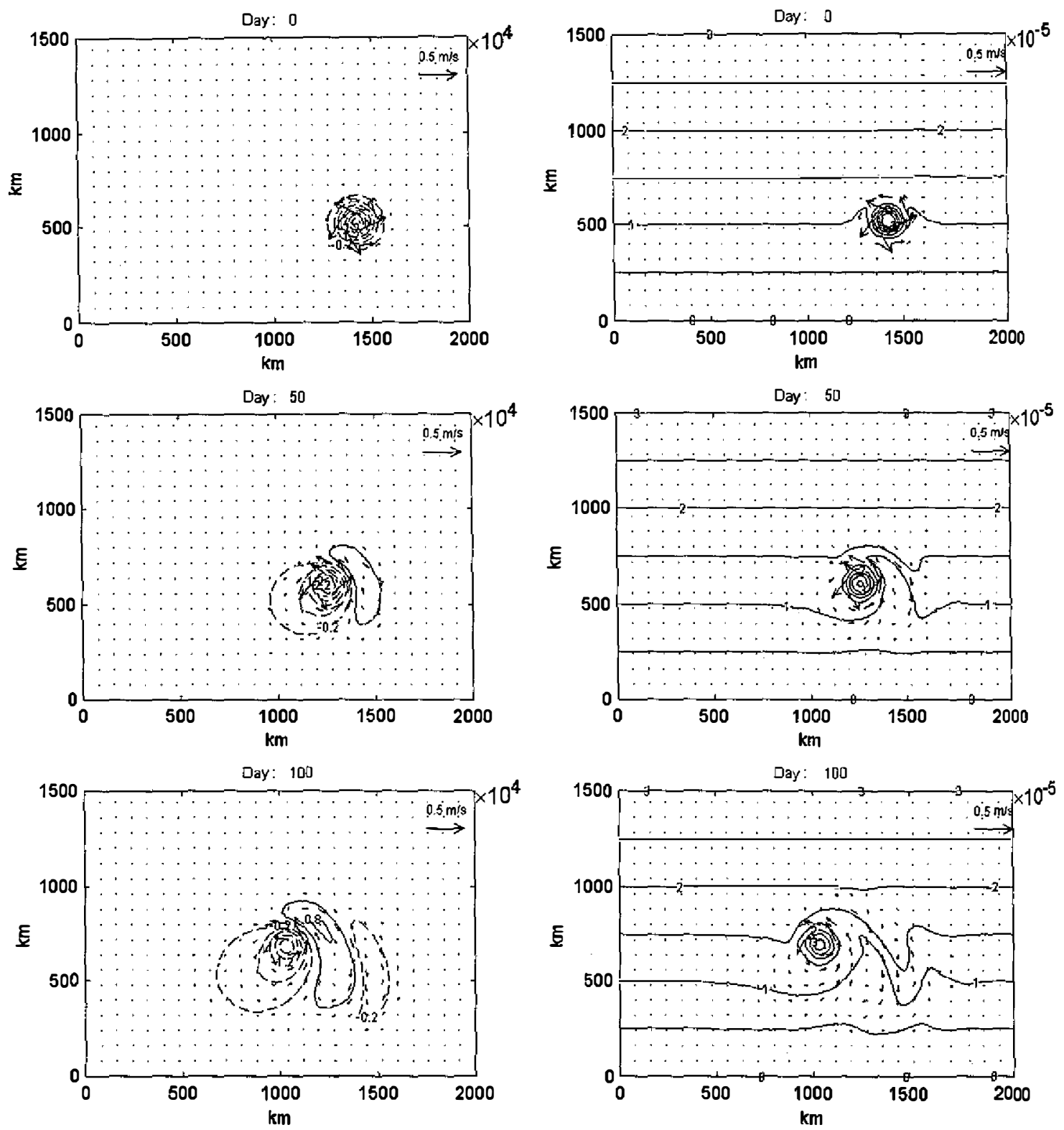

Fig. 9. Contours of the stream function (SF, $\mathrm{m}^{2} \mathrm{~s}^{-1}$, left column) and poten tial vorticity ( $\mathrm{PV}, \mathrm{s}^{-1}$, right column) every $\mathbf{5 0}$ days for the zero background flow case. Contour intervals are $0.5 \times 10^{4}$ for SF and $0.5 \times 10^{-5}$ for PV. 

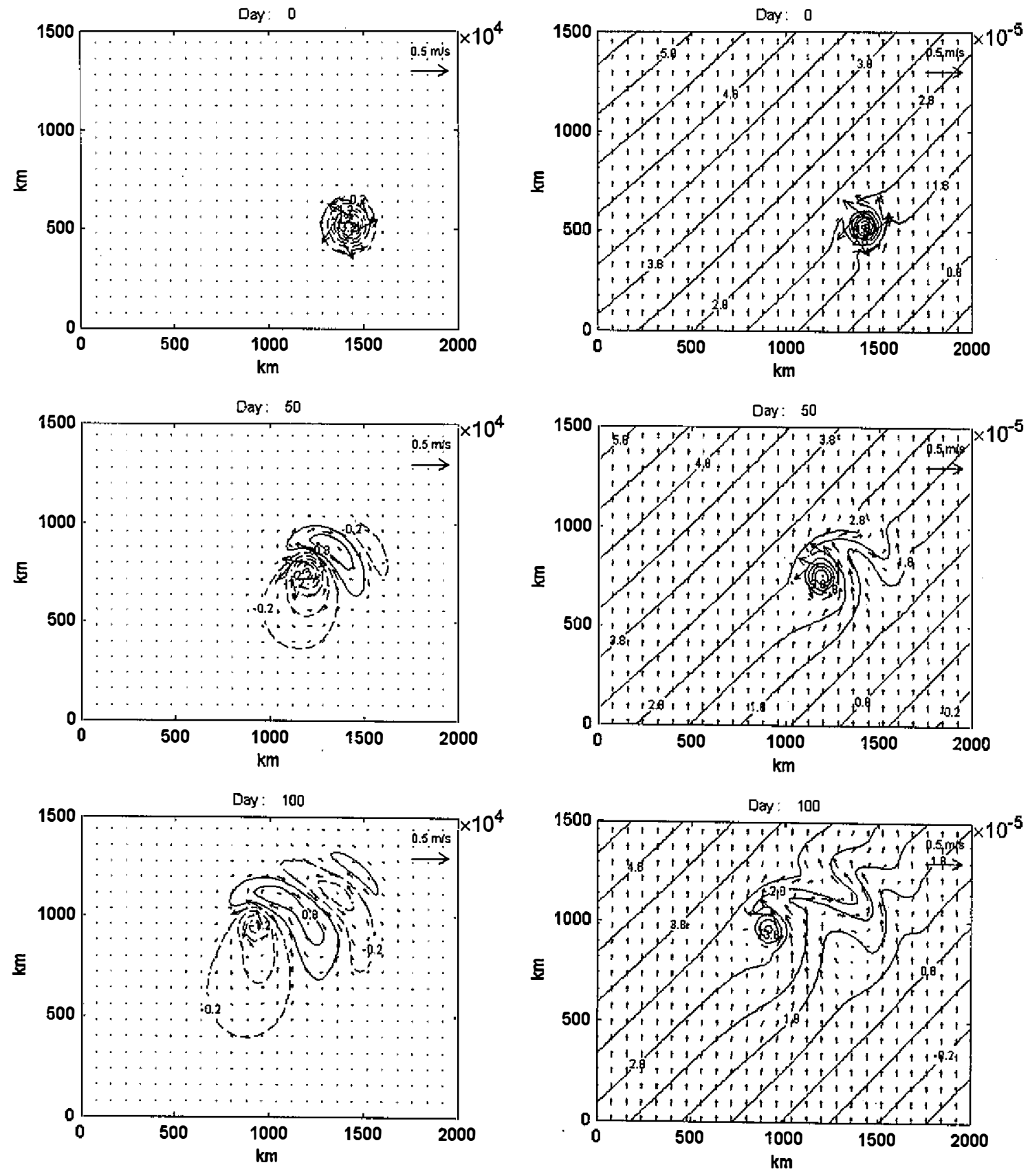

Fig. 10. Contours of the stream function (SF, $\mathrm{m}^{2} \mathrm{~s}^{-1}$, left column) and potential vorticity (PV, $\mathrm{s}^{-1}$, right column) every 50 days for the northward background flow case $(\mathrm{V}=6 \mathrm{~km} /$ day). On the left column, mean (background) values for SF and velocity are removed. Contour intervals are $0.5 \times 10^{4}$ for SF and $0.5 \times 10^{-5}$ for PV. 


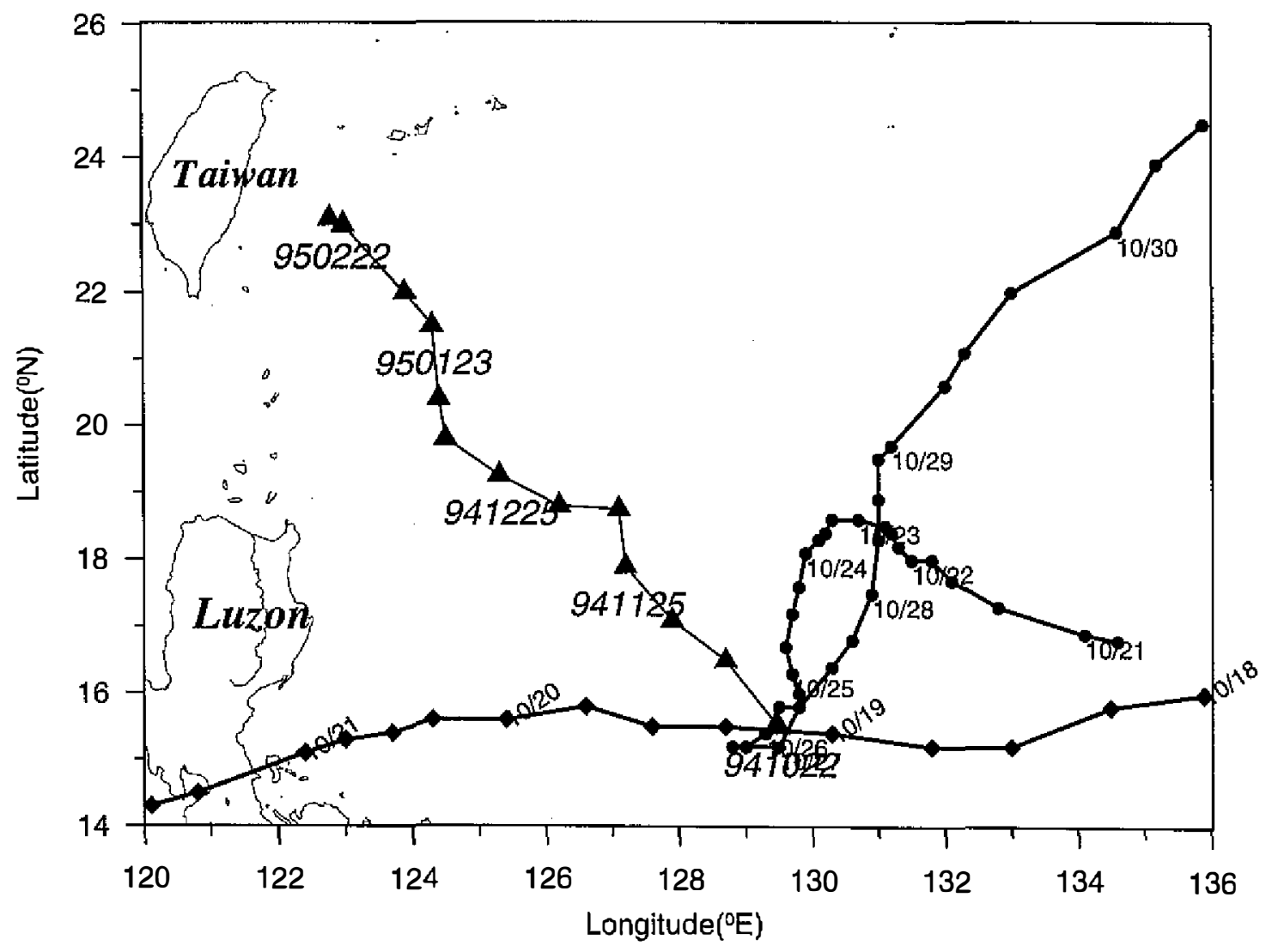

Fig. 11. Trajectories of eddy $9410 \mathrm{~L}(\boldsymbol{\Lambda})$ and Typhoon Verne $(\bullet)$ and Teresa( $\bullet)$. Dates are marked aside their symbols. Both typhoons appeared in October 1994.

time. Therefore, the study of $9410 \mathrm{~L}$ becomes very important as it shows the strong possibility of typhoon-induced eddies in the low latitude of the northwest Pacific.

By imposing a weak mean northward flow, the quasi-geostrophic model is able to explain the observed northward propagation. The model results of westward propagating speed at 4 $\mathrm{km} /$ day (no background flow case) and $5 \mathrm{~km} /$ day (with northward background flow case ) are slightly less than the observed averaged value of $6.5 \mathrm{~km} /$ day. Nof(1981) and Cushman-Roisin et al.(1990) have shown the value of westward $\beta$-drift for eddies $\left(0.32 \beta_{0} R d^{2} \sim 0.67 \beta_{0} R d^{2}\right.$ for Nof and $\sim \beta_{0} R d^{2}$ for the later, respectively), the observed $6.5 \mathrm{~km} /$ day seems to be larger than theoretical predictions. As mention in the previous sections, eddy $9410 \mathrm{~L}$ propagated in the southwest part of the subtropical gyre, the initial position might very well located in or near the North Equatorial Current (NEC). Currents in NEC might carry the eddy westward, and hence increase the propagation speed during the early stage of $9410 \mathrm{~L}$. In addition, the initial complex structure of 9410L (oval-shaped and two SSHA minima, Fig. 2) might not be explained satisfactorily by a simple eddy used in the model or theoretical studies. The evolu- 
tion of 9410L might also play an important role in propelling itself toward the west.

The model also predicts the formation of a strong anticyclonic eddy behind the leading cyclonic eddy. It is interesting that a strong anticyclonic eddy indeed has appeared behind the cyclonic eddy during cycles $82-85$ (Fig. 2). One is tempted to believe that the observed anticyclonic eddy was originated from eddy $9410 \mathrm{~L}$. The fate of the cyclonic/anticyclonic eddy pair, however, cannot be determined from the present data. The phenomena of phase tilt of eddies can not be solved in our 1.5-layer reduced gravity model. To aim at this issue, a multiple layer model is more suitable for further study of the vertical structure of eddies. The circumstantial evidence, nevertheless, suggests that they might interact strongly with the Kuroshio and ultimately be responsible for the observed low transport through ETC.

Acknowledgments The authors would like to thank Dr. Cheinway Hwang of National Chiao Tung University for providing the Topex/Poseidon Altimetry data and the anonymous reviewer for valuable comments.

\section{REFERENCES}

Archiving, Validation, and Interpretation of Satellite Data in Oceanography (AVISO), 1992: AVISO User Handbook. Merged TOPEX/POSEIDON Products, Rep. AVI-NT-02-202$C N$, Ed. 2.1, Cent. Natl. d'Etudes Spatiales, Toulous, France.

Cartwright, D. E., and R. D. Ray, 1991: Energetic of global ocean tides from Geosat altimery. J. Geophys. Res. 96, 16 897-16912.

Cushman-Roisin, B., 1990: Westward Motion of Mesoscale Eddies. J. Phys. Oceanogr, 20, 758-768.

Cushman-Roisin, B., 1994: Introduction to Geophysical Fluid Dynamics. Prentice Hall Inc., Englewood Cliffs, New Jersey 07632, 320 pp.

Hwang, C., 1996: A study of the Kuroshio's seasonal variability using an altimetric-gravimetric geoid and TOPEDX/POSEIDON altimeter data. J. Geophys. Res., 101, 63136335.

Johns, W. E., T. N. Lee, D. Zhang, R. Zantopp, C. T. Liu, and Y. Yang, 2001: The Kuroshio East of Taiwan: Moored Transport Observations from the WOCE PCM-1 Array. $J$. Phys. Oceanogr, 31, 1031-1053.

Leaman, K. D., R. L. Molinari, and P. S. Vertes, 1987: Structure and Variability of the Florida Current at $27^{\circ} \mathrm{N}$ : April 1982-July 1984. J. Phys. Oceanogr, 17, 565-583.

McWilliams, J. C., and G. R. Flierl, 1979: On the Evolution of Isolated, Nonlinear Vortices. J. Phys. Oceanogr, 9, 1155-1182.

Mellor, G. L., and T. Ezer, 1991: A Gulf Sream model and an altimertry assimilation scheme. J. Geophys. Res., 96, 8779-8795.

Niiler, P. P., and W. S. Richardson, 1973: Seasonal Variability of the Florida Current. J. Mar. Res., 31, 144-167.

Nof, D., 1981: On the $\beta$-Induced Movement of Isolated Baroclinic Eddies. J. Phys. Oceanogr, 11, 1662-1672.

Qiu, B., 1999: Seasonal eddy field modulation of the North Pacific Subtropical Countercurrent: 
TOPEX/Poseidon observations and theory. J. Phys. Oceanogr, 29, 1670-1685.

Qu, T., H. Mitsudera, and T. Yamagata, 1999: A Climatology of the Circulation and Water Mass Distribution near the Philippine Coast. J. Phys. Oceanogr, 27, 1488-1505.

Roemmich, D., and J. Gilson, 2001: Eddy Transport of Heat and Thermocline Waters in the North Pacific : A Key to Interannual/Decadal Climate Variability? J. Phys. Oceanogr., 13, 675-687.

Rutherford, I. D., 1972: Data Assimilation by Statistical Interpolation of Forecast Error Fields. J. Atmos. Sci., 29, 809-815.

WOCE/PO-DAAC, 1998: Atlas and Ardizzone SSMI-derived winds, version 2, PO-DAAC gridding. In WOCE Satellite Data CD-ROM Version 1.0. A contribution to WOCE, published for the WOCE Conference, Halifax, Canada, May 1998.

Yang, Y., C. T. Liu, J. H. Hu, and M. Koga, 1999: Taiwan Current(Kuroshio) and Impinging Eddies. J. Oceanogr, 55, 609-617.

Zhang, D., T. N. Lee, W. E. Johns, C. T. Liu, and R. Zantopp, 2001: The Kuroshio East of Taiwan: Modes of Variability and Relationship to Interior Ocean Mesoscale Eddies. $J$. Phys. Oceanogr, 31, 1054-1074. 